\title{
Confronting Colorblind Commodity Racism: Young Jean Lee's The Shipment
}

\section{Seunghyun Hwang}

Incheon National University

\begin{abstract}
Surrounded by the hubbub of the 2008 presidential election, playwright Young Jean Lee considered a topic for the next project of her nonprofit experimental theater company and decided to write a black identity politics show that addressed the issues of commodity racism and perceived colorblindness. Her objective, in collaboration with five African American actors, was to expose both conscious and unconscious racial stereotyping deeply rooted in American culture and to lead the audience to connect the abstract element of racial stereotyping to the actual experiences of minority individuals. This article focuses on the development process of the 2008 project and connects it to the social, cultural and political influences that guided the process to demonstrate how the production fits into the historical landscape of dramatic literature and to illustrate the power of the performing arts as a catalyst to initiate public dialogue and to bring to the forefront the questioning of discriminative societal attitudes and practices.
\end{abstract}

KEYWORDS: commodity racism, perceived colorblindness, racial stereotyping, identity politics

The 2008 presidential election in the United States once again brought the factor of race strongly into the public discourse. A National Public Radio broadcast declared that some considered Barak Obama's bid for the presidency as "a post-racial triumph" and that "Obama seemed to embody the hope that America could transcend its divisions"; however, the same program warned that the country "may have a way to go yet to reach colorblindness" (“A New”). 
Amid the election frenzy, playwright Young Jean Lee considered a topic for the next project of her nonprofit experimental theater company. To select the focus, Lee posed the question, "[w]hat's the last play in the world I would ever want to write?" ("Young," Foundation). She explained that she uses this approach "because going out of my comfort zone compels me to challenge my assumptions and find value in unexpected places" ("Young," Foundation). Her answer was a black identity politics show. As the company's artistic director, Lee chose to address the issue of colorblindness in terms of the hypocrisy of a post-racial political era being declared by a society that openly consumed black stereotypes as a form of commodity racism. As a Korean American, she selected racial prejudice and African American stereotypes "in part to confront her own biases" and with the intent to make the play "about improving communication across racial lines" (Soloski, "Playwright").

Tensions in race relations between African Americans and Asian Americans "go back for many decades" supported by generational mistrust reinforced by Asian parents warning their children "to be fearful of black people" (Cho, "Asian"). ${ }^{1}$ Differences in the application of stereotypes have, at times, brought the two minorities into conflict. For example, the "stereotype of Asians as industrious and rule-abiding" was popularized "in direct contrast to African-Americans, who were still struggling against bigotry, poverty and a history rooted in slavery" and was used as a racial wedge between the two groups (Chow, "Model"). The popularization of the model minority stereotype would not have occurred "without the concomitant stereotype of the lazy and unintelligent Black or Brown other" (Li, Model ix). One of the most noted clashes between the two minorities occurred during the Los Angeles riots in 1992, in which black residents rioted over a nationally televised court decision that acquitted white police officers of the beating of Rodney King, a black motorist. In the rampage, stores in predominantly black neighborhoods, many of which were owned by Koreans, were vandalized. This type of confrontation between the two minorities has been blamed on culture and/or race as well as "structural forces in race relations - for instance, the commercial role of minority middle men" like the Korean merchants who were "the intermediary between a local popula-

1 In support of the Black Lives Matter movement many young adult "Asian Americans are increasingly engaging in difficult conversations with their parents and community about uprooting their anti-black sentiments and supporting African Americans" (Ebrahimji and Lee, "Meet"). 
tion and individuals in economic and political power" (Park, "Use" 492). In 2008, the tension between the two groups was less apparent, and many Asian Americans and African Americans supported a black man for president (Cervantes, "Poll").

In light of the presidential election, it is not surprising that Lee chose the issues of politics and black identity as the focus of the new project. All of the Young Jean Lee's Theater Company's productions focused on "major issues in unpredictable and complicated ways that stick in people's minds and challenge them to think rather than reaffirming their pre-existing beliefs" (Gatlin, "The Theater"); for example, white privilege and identity (Straight White Men 2014), gender and identity (Lear), and religion and identity (Church). So with the possibility of Barack Obama being elected president, Lee decided to write a black identity politics show that addressed the issues of commodity racism and perceived colorblindness.

Anne McClintock introduced the term commodity racism in relation to the British use of racial images to sell products and amplify colonialism (McClintock, "Soft-Soaping" 130-33). Commodity racism lowers the status of the racial group represented in the images and appropriates elements of that group's culture for capitalistic or political gains. Elizabeth Chin extended the concept to include slavery "since it was racism itself that justified turning people into commodities"; she also associated the term with the commodification "of Asian children as attractive adoptees" (Chin, "Commodity" 100). The idea of colorblindness, as referenced in the NPR broadcast, is an elimination of any consideration of race. To some people, colorblindness is perceived as a positive approach to the elimination of racism. However, to others, it is considered as a way to maintain "white privilege by negating racial inequality" (Gallagher, "Color-Blind" 24).

Young Jean Lee considered various approaches to the design of the 2008 project with the intent to provoke introspective thought on race. This article focuses on Lee's development process from the initial workshops in New York in April to the premiere of The Shipment in Columbus, Ohio in November and on the social, cultural and political influences that were relevant to Lee's stated purpose of the play as a black identity politics show. The discussion of this play illustrates the power of the performing arts as a catalyst to initiate public dialogue and to bring to the forefront the questioning of discriminative societal attitudes and practices. 


\section{Production Design}

Lee's production design process was twofold. First, she needed to find a way to challenge her audience to rethink their acceptance of the stereotypes of African Americans sold as commodities. Research supports that "racial minorities are overrepresented as criminals or perpetrators compared to their White counterparts in media but also that this media bias promotes public hostility toward those groups" (Dukes and Gaither, "Black" 790). Additionally, "mass media are a major source of entertainment and the main source for news for most people" and from theses sources people "tend to reinterpret the messages to reinforce their preexisting beliefs and attitudes" (Perse and Lambe, "Media" 14). The commodifying images of African Americans that often appear in mass media involve drugs, prostitution, incarceration, violence, and crime. Lee wanted the play to focus on how these stereotypes become commodities of racism sold as entertainment and purchased by both mainstream and minority consumers. Second, Lee needed to address the application of perceived colorblindness that supports statements used to deny the existence of racial biases, such as "some of my best friends are black" (Eligon, "The Some").

Critical Race Theory is a theoretical approach used by scholars to investigate how the concepts of race and racism are expressed in the dominant culture and how the perceptions related to the concepts of race affect minorities who are victimized by systemic racism existing in the particular culture. CRT considers race as a product of social thought "that society invents, manipulates, or retires when convenient" or "in response to shifting needs" (Delgado and Stefancic, Critical 9). In other words, the dominant voice in the society changes the elements related to race to fit the social mood of the time period. Race is a way of categorizing identity that is based on physical traits and is often only considered in terms of African Americans and non-Hispanic white Americans. This binary model "renders other racial groups invisible" (Dudziak, Cold War 14). Juan Perea explained that since "the black-white binary paradigm is so widely accepted, other racialized groups like Latinos/Latinas, Asian Americans, and Native Americans are often marginalized or ignored altogether" (Perea, "The Black-White" 459). Similarly, Lee expressed the opinion that few people in 2008 cared about Asian American issues while African American issues were often front-page news. She maintained that both racial groups, whether ignored or sensationalized by mainstream media, should not neglect the fact that the culture contains coded messages of racism, even with the possible election 
of a black president. ${ }^{2}$ In a similar vein, Delgado and Stefanic noted that "racism continues to blight the lives of people of color, including holders of high-echelon jobs" (Delgado and Stefanic, Critical 11).

The identities of both African Americans and Asian Americans have deep historical connections to discriminative practices in America. Both groups have been targeted by prejudicial stereotyping that reduces or limits their status in society. For example, African Americans have struggled to break down racial stereotypes rooted in the materialism of American slavery that treated them as products. Asian Americans have been saddled with the stereotype of expendable foreigner, which was rooted in the country's historical westward expansion that portrayed them as foolish menials and the modern stereotype of model minority, which "creates great pressure to conform to the white-dominated culture" (Cho, Myth 3).

To challenge the audience to think about the demeaning and marginalizing effects of applications of stereotypes, Lee chose to focus on the sale and purchasing of minority stereotypes as commodities. She attempted to generalize the issue by staging a play about African Americans that was written and directed by an Asian American. Lee assumed that her decision to bring the African American experience to a mainstream and minority audience contained a certain degree of risk because she was "a nonblack playwright, someone possessing no lived, practical knowledge of the black experience" (Hatch, "First" 104). She anticipated a possible sense of mistrust concerning her authority or ability to write about black experiences and expected that many audience members, both minority and mainstream, might leave during the show. ${ }^{3}$ In an interview, she explained, "I think that people are already weirder and more defensive about racism against black people than they are about other kinds of racism. I thought it was going to be this huge issue that I wasn't black" (Del Signore, "Young Jean"). To directly address the anticipated issue, Lee decided to appear on stage prior to

2 Young Jean Lee stated these opinions during the development of The Shipment at the Wexner Center for the Arts at The Ohio State University. I had an internship connected to her residency project and took notes throughout the development process. The notes included information from Lee's talkback sessions with the audience after each show and from conversations with Young Jean Lee, the actors and staff members. Throughout this article explanations attributed to Young Jean Lee without specific citations and observations of the process come from these notes.

3 During each Wexner Center performance some people left the theater, mostly during the stand-up comedian section of the play that contained racial and sexual jokes using foul language. 
each performance and introduce herself as an Asian and a Korean American playwright and director and that she intended to describe African American experiences of commodity racism. To gather audience input, Lee conducted question and answer sessions after each performance. ${ }^{4}$ During the talkback sessions, some audience members commented that Asian Americans' experiences of racism differ from African Americans' experiences and that Lee's ancestors came to the United States by choice where the ancestors of African Americans came involuntarily as slaves. Thus, with these essential differences, the playwright could not have firsthand knowledge. In response, Lee explained that being black, in terms of the message of her play, was not only about people of African heritage but also about Asians, Latinx, and other non-white minorities. Robert Blauner showed agreement with both the audience members and Lee by noting the involuntary nature of the black experience in contrast to the voluntary Asian diaspora and that both groups "have faced intense color prejudice" (Blauner, "Internal" 88).

Lee's thoughts are in line with the voice-of-color thesis of CRT in that minority groups have insights about race and racism based on their own "experiences with oppression" and are in a position to "communicate to their white counterparts matters that the whites are unlikely to know" (Delgado and Stefancic, Critical 10). Lee recognized that she lacked the specific experience of African American discrimination. However, as an Asian American she had experienced discrimination. Growing up in "a very small, very white town" Lee was shunned by the other children and spent "her childhood and adolescence in intense isolation" (Sehgal, "Young"). Also, the position of not being black and not being white allowed Lee to be a middle ground facilitator, and her personal experience as a minority gave her insight to communicate the effects of racism to non-minority audience members.

\section{Staging Race}

For the development of the project, collaboration with the African American actors was especially vital since Lee had no direct African American

4 Lee used the input to improve the effect of the play. In Europe she received comments of sympathy "about America's appalling attitudes toward race relations" (Soloski, "Playwright"), which led to added dialogue such as "the fact that y'll don't SOCIALIZE with YOUR darkies don't mean you ain't racist, it just mean you even MORE fucked-up!” (Y. Lee, The Shipment, 12). 
experiences to rely upon to form a perspective of authenticity. Instead, she contributed her writing and directing skills, an established theater company with the financial backing of an artist residency award, and the passion for actively tackling the difficult topic. Her objective was first to lead the audience to connect the conscious application of racial stereotyping to the actual experiences of minority individuals then to initiate awareness of unconscious racial bias by shocking them into considering that "[e]ven among the most well-intentioned and consciously egalitarian people [...] non-conscious associations about ethnic groups still have a pernicious effect on behavior and attitudes" (Rigoglioso, "Unconscious"). To accomplish this, she needed to develop a basic framework and hire actors with the necessary skills and enthusiasm for the topic.

To develop the basics, Lee organized two workshops in New York. Her original intent, based on her assumptions of African American culture, was to introduce hip-hop concepts into the flow of the play. From Lee's perspective, hip-hop seemed like a reasonable choice to stage stereotypes. However, by 2008 hip-hop was popular, especially in New York. Beginning with the success of Run DMC's "My Adidas" in 1986, hip-hop "began to appeal and sell to consumers from zip codes where rap wasn't even on the radio [...] Suburban, white zip codes" and was "an invitation to join in the cool it embodied" (Stoute, "The Tanning" xviii). Lee's initial attempt to manipulate the audience into reconsidering the negativity of stereotypes through hiphop was not successful. She explained, "the cast members were ironically doing all of these really stereotypical dances onstage and started encouraging the audience to come up and dance with them. We didn't think anyone would, but all these people jumped onstage and started dancing, thinking it was a genuine moment" (Brillson, "Young Jean"). Lee's assumption that the stereotypical dance moves would create discomfort for the audience and the audience's interpretation of the dancing as an authentic experience were diametrically opposed. So she decided to take a different approach to create the disquietude that would initiate introspective thought.

Lee solicited input from her friends who were African American and learned that for black actors the "likelihood of being hired for movie roles depended on how 'black' or 'street' or 'real' they could act" (Als, "Real"). The same kind of stereotypical casting was applied to Asian American actors who were told by directors that they were not "real" as "orientals" unless they use broken English and stereotypical Asian mannerisms (qtd. in E. K. Lee, A History 24; qtd. in Paik, "The East" 14). Based on this in- 
formation, Lee decided to use the stereotyping of roles in the entertainment industry as the project framework.

An Artist Residency Award from the Wexner Center for the Arts provided production assistance to continue the project at The Ohio State University ("Performing"). Five African American actors joined Lee in the second stage of the development process: Mikeah Ernest Jennings, Jordan Barbour, Prentice Onayemi, Douglas Scott Streater, and Amelia Workman (Y. Lee, The Shipment 4). Applying a collaborative writing style, Lee encouraged the actors to freely express their opinions and suggest changes at every stage of the play's development. To discover which elements would best provoke thought about the black experience, she asked the five actors to describe the stereotypes that they had individually experienced and to incorporate their own emotions and experiences into the development of the project (H. Shaw, "Black").

The titles of Young Jean Lee's plays have symbolic meanings. The title for this project, The Shipment, was inspired by a rap song. Lee explained, "it was meant to be about a shipment of drugs, but for me it kind of evokes the idea of the African slave as a shipment in the way a box of books from Amazon is a shipment" (Del Signore, "Young Jean"). The two concepts Lee connected through the title are the trafficking of human flesh and the marketing of racially commodified products.

The title's connection to enslaved human beings treated as property matches with events from American history, such as the case of Henry "Box" Brown. Brown was born a slave on a plantation in 1815. After his wife and children were sold and sent to another state, he devised a plan to ship himself to a state that had outlawed slavery. Brown successfully made the 27-hour journey "in a box 3 feet long by 2 feet 8 inches deep by 2 feet wide" and traveled "by a variety of wagons, railroads, steamboats, ferries, and finally, for added safety, a delivery wagon that brought the box to the Philadelphia Anti-Slavery Society" (Walls, "Freedom"). Another example of labeling humans as property occurred during the Civil War. To circumvent the Fugitive Slave Law of 1850 that required a runaway slave be returned to the owner, fugitive slaves were not considered as free but were "classified as property" and "declared to be "contraband of war"" ("Living"). Even after the addition of the thirteenth amendment to the Constitution (1865) that abolished slavery as well as the fourteen (1868) that granted citizenship to African Americans and fifteenth (1870) that gave voting privileges to black men, the deep-seated prejudice associated with the dehumanization aspect 
of slavery remained in the culture's racial stereotypes. The stereotypes supported an implied citizenship designation to African Americans of being free but not equal in the society. The Civil Rights Act of 1964 outlawed discriminative activities involving race, color, religion, sex, or national origin. However, the dual concepts of inclusion and unequal were sustained by the stereotypes and legalized by state and local laws that enforced racial segregation.

To bring awareness of both conscious and unconscious racial assumptions, Lee designed a double narrative structure for The Shipment. The first narrative, "Stereotype," displayed obvious racial expectations; the second narrative, "Naturalistic," held hidden preconceptions about race. Both narratives were presented by the same actors but utilized different approaches. "Stereotype" used typecasting based on the actor's appearance. "Naturalistic" featured colorblind casting, a casting method in which the actor's race or ethnicity is not considered. The final two statements of the play connected the two narratives and exposed the issue of conscious and unconscious commodification of a group of people based on race. It was the shocking ideas revealed in the closing lines of dialogue that were designed to create awareness of discriminative societal attitudes and practices related to racial stereotyping.

\section{Narrative 1: "Stereotype"}

Young Jean Lee described the first narrative of The Shipment as "kind of structured like a minstrel show, and we didn't want anything to resemble anything that would actually be in a real minstrel show" (Del Signore, "Young"). It included a dance number, a comedy bit, and a condensed drama. Lee's quasi-minstrel was in line with the three-part structure of the traditional minstrel show that was developed by the Christy Minstrels in the 1840s. The traditional structure incorporated "a dance called the "walk around" "then "a long oration delivered by a dimwitted character trying to speak eloquently, delivering bitter social messages without offending the audience" and finally "a skit set on an idyllic plantation with an Uncle Tom character" (Adams, "Joyce" 37-38).

Minstrels were a popular form of entertainment, especially in the American South, from the 1840s to the early 1900s. The shows utilized blackface, a form of cross-dressing. In cross-dressing, "one puts on the insignias of a sex, class, or race that stands in binary opposition to one's own" (Ro- 
gin, Blackface 30). In the minstrels, white actors would blacken their faces and perform "a range of negative stereotypes of African Americans including being lazy, ignorant, superstitious, hypersexual, criminal or cowardly" (Clark, "How"). This type of racial cross-dressing "involves temporarily adopting the imagined characteristics of a black Other" and "also indirectly reinscribes racial hierarchies and affirms whites' presumed superiority" (Evan, Writing 84). With the abolition of slavery in 1865, the dominant position of whites, particularly in the southern states, was challenged, and this led to an "anti-black propaganda" element in minstrel shows that was aimed "to demean and dehumanize African-Americans" to reduce their political power and societal status (Pitner, "Behind").

Some sociologists attribute the development of race relations in the United States to the concept of internal colonialism. Internal colonialism deals with the oppression of a minority or ethnic group. Robert Blauner "first used the term in regards to black Americans" (Chavez, "Aliens" 790). The concept suggests that slavery led to the development of a colonizer and colonized relationship between whites and blacks. In colonialism as traditionally defined, the external colonizer subordinates the group native to the territory. Internal colonialism applies the subordination concept to minority groups within a society and can be understood in terms of "the historical development of ethnic and racial inequality in the modern world" (Chávez, "Aliens" 787). Blauner explained, "that classical colonialism of the imperialist era and American racism both developed out of the same historical situation and reflected a common world economic and poser stratification" and that "a common process of social oppression characterized the racial patterns in the two contexts" (Blauner, "Internal" 84). In this line of thinking, the minstrel, with the purpose of social suppression of a racial group that had been considered as property, supported the racial patterns of the commodification of blacks developed by the institution of slavery.

By employing a quasi-minstrel framework that featured modern caricatures, Lee connected the consumption of the minstrel (a recognized bigoted and suppressive form of racial commodity entertainment) to the consumption of modern race-specific entertainment products. To structure "Stereotype" as contemporary entertainment, Lee and the five actors discussed various stereotypical caricatures. They selected "recycled African-American stock characters performed with just enough off-kilter subtext to make theatergoers re-examine them" (Grossberg, "For Playwright"). They placed each character type in an entertainment field: dance, comedy and drama. 
"Stereotype" opened with a dance sequence. During the early rehearsals at the Wexner Center, Lee asked two of the male actors, Prentice Onayemi and Mikeah Ernest Jennings, to dance to fast-paced music on an illuminated stage. The effect of their dancing at first mirrored the New York workshops. Lee then experimented with the lighting. When the stage was darker, the dance moves that the two men chose became more buffoonish and marionette-like. From time to time, the actors would cease the silly dancing and stare toward the audience with serious looks then begin to dance again. These interruptions served to disrupt the stereotype and show the dancers as real people. One of the dancers wore "a black suit, white shirt, flowered vest, red tie, black flowered lapel brooch, and white shoes" and the other wore "a black tuxedo with a white shirt, black suspenders, black cummerbund, and black bow tie" (Y. Lee, The Shipment 7). These costume selections made a loose connection to the traditional minstrel in which the white actors in blackface "would dress up in ill-fitting clothes, rags or approximations of tuxedos" (Pitner, "Behind"). Also, with the minimal lighting and dark clothing, the dancers at times appeared as disembodied stark white shirt collars and cuffs and white shoes. Lee also used music as a subtle layer of meaning to compliment the actions on stage. For this sequence, she chose "Fascinating New Thing" by the alternative rock group Semisonic. The lyrics of the song suggest a feeling of discovery and enjoyment of someone referred to as a thing, in other words, a dehumanizing term of endearment.

As a transition to the comedy sequence, Lee chose hip hop rapper Lil Jon's "I Don't Give A Fuck." This choice of music represented the commodity of stereotypical language sold as gangsta rap and foul-mouth black comedy acts. Lee explained in a talkback session that she used the plot and style of the play to express her strong opinion that mass media amplifies and maintains the stereotypes of inferiority or immorality of people of color through repeated rebroadcasting and reproduction. As an example, she highlighted the baseness and vulgar language of a black stand-up comedian. A 1994 article in Jet magazine, "Can Young Comedians Be Funny Without Using Profanity," explained the origin of this stereotype. Before young black comics began to use "graphic descriptions of sex, four-letter words and a ton of negative words to describe women" they had difficulty finding work, but after adding them to their acts, the comedians were "among the hottest on the comedy circuit" ("Celebrities" 32). The article predicted that the trend would not last long. Nonetheless, the debasing trend did last and 
became a lucrative stereotype that turned the African American comedian into a commodity of racism purchased and enjoyed by both majority and minority consumers.

To develop the stand-up comic caricature, Lee asked Douglas Scott Streater to go on an unscripted rant about American racism for as long as he could. Streater's rant was videotaped to capture the actor's words and body language. Lee then selected parts of Streater's rant as the basic dialogue for the comedy sequence. The comedian character glibly delivered fast-paced sexual and racial jokes in a similar style to stand-up comics like Dave Chappelle and Richard Pryor. The character was described as a "talkative thug" and as violently "[h]olding his mike like a billy club" (Als, "By the Skin").

The comedian's comments were intended to insult and shock the white segment of the audience; for example "Now I don't mean to be offensive by sayin' this, but - white people be evil" (a parody of the "I'm not a racist but..." justification) and "I gotta talk about RACE because white people be some stupid-ass mothafuckas" (Y. Lee, The Shipment 11). The dialogue addressed the concept of perceived colorblindness: "And all a you people who consider yourselves to be 'color-blind'? Y'all are the WORST mothafuckin' offenders. What is that shit? Color-blind. That's some bullshit right there. (He gestures to his face.) Does this look like a TAN to you, mothafucka?" (Y. Lee, The Shipment 12). The comic ended his set with a sudden transition from the stereotype to the real African American man standing on the stage. ${ }^{5}$

The third sequence focused on the world of hip-hop. In the late 1970s, hip-hop "was a marginal urban subculture, largely confined to two of the most notorious ghettos in the United States, Harlem and the South Bronx" that then grew within thirty years into "a multibillion-dollar industry, transcending entertainment and moving into consumer products and services" (Charnas, The Big ix). Hip-hop is composed of four elements: rapping, breakdancing, DJing and graffiti, with rapping developing as the most prominent (S. Shaw, "The Difference"). Revolving around rapping, the third sequence contained a series of short skits about the rise and fall of a young black man.

For many years, films and television programs presented truncated depictions of the lives of inner-city African Americans and in so doing co-

5 "I got a white wife. She got blond hair, blue eyes, and BIG titties." (spoken as stereotype character) "She's also the most wonderful person I've ever known, and I love her and my mixed tan babies more than anything in the world." (spoken as the actor) (Y. Lee, The Shipment 15-16). 
opted black culture in a commodified form that did not depict reality but rather treated African Americans as stereotypes, for example Huggy Bear, the black character who was a flamboyantly dressed semi-retired pimp and police snitch, in the TV drama Starsky \& Hutch. This section of the play was "Lee's mordant commentary on the simplicity of the dominant narratives of black urban dysfunction and/or achievement" (Isherwood, "Off-Center"). To draw attention to this type of cultural simplification, Lee directed the actors to adopted the acting style of deadpan surrealism. They recited their lines "as mechanically as possible, perhaps in an effort to separate meaning from content" (Isherwood, "Off-Center"). Additionally, the darkened stage lighting and dark-colored costumes gave the skits an abridged and minimal staging sense.

The storyline revolved around the character Omar, a black teenager who longed to be a rap star despite his mother's wish that he become a doctor. As the drama progressed, Omar was led astray by his street-smart friend, Drug Dealer Desmond. A quick progression of stereotypical scenes of drug dealing, drive-by shooting, black-on-black crime, incarceration and Black Muslim conversion, female exploitation and infidelity, and coke-snorting/ syringe wheeling drug addiction lead to Rapper Omar's attainment of a highly successful rapping career. Eventually, an adult Omar bemoaned the emptiness of his life, saying, "I feel that here is nothing to live for except drugs and sex and unhealthy foods. [...] I have grown to hate the very rap that I once loved. Sometimes I don't even feel like taking a shower!" (Y. Lee, The Shipment 28). Omar's commentary was a subtle reference to a form of racism that puts the blame for failure on Black culture (Powell, "Relying" 107; Treviño, Investigating 76).

Omar ended his depressing soliloquy with "Please Lord, show me the way!" (Y. Lee, The Shipment 28). An answer to his plea came from his Grandma in Heaven. Grandma in Heaven told Rapper Omar a fable in the style of African folklore. Richard Wright explained the importance of this traditional form of literature: "In the absence of fixed and nourishing forms of culture, the Negro has a folklore which embodies the memories and hopes of his struggle for freedom" (Wright, "Blueprint" 100).

In the final portion of the first narrative, Jordan Barbour (Rapper Omar), Amelia Workman (Grandma from Heaven), and Prentice Onayemi (Drug Dealer Desmond) stepped out of character and stood directly facing the audience. To accentuate the change of perspective Lee manipulated the lighting in the theater and brought up the house lights to illuminate the audience 
seating area. The three black actors stood center stage and gazed directly at the audience members. This gave a mirroring effect with the actors watching the audience and the audience watching the actors. Without moving or speaking, the expressionless actors scanned the audience with their eyes. Lee explained her directorial intention as "[t]he audience is laughing at these stereotypes, and suddenly they see the performers as people, not stereotypes, and the performers are looking at them" (Del Signore, "Young"). To build the intensity, the stage direction instructed the actors to "look at the audience for an uncomfortably long time" (Y. Lee, The Shipment 29). The discomfort was intended to shock the audience into awareness that their conscious enjoyment of the racial stereotypes was a form of commodity racism. The silence was abruptly broken as the three actors began to sing a three-part harmony a cappella version of the indie rock song "Dark Center of the Universe." The song was sung without a discernible music genre style "to strip it of any sort of black signifiers" and "any of the baggage or stereotypes that comes from the more dubious consumption of black performers" (Del Signore, "Young"). Lee explained that she used the song as a way to regain the audience's attention after the discomfort created by the silent staring.

\section{Narrative 2: "Naturalistic"}

Customarily, set transitions happen behind a closed curtain or on a dark stage. Lee, however, used the transition between the narratives to set up nuance for the remainder of the play. In full view of the audience, two stagehand characters, "both white males over the age of fifty, wearing blue jeans," carried on and arranged living room furniture that looked "modern, expensive and masculine" (Y. Lee, The Shipment 30-31). After the set was complete, a race/age/class juxtaposition based on appearance was visible as the two white actors left the stage and two young black actors dressed as professionals entered.

During a talkback session, Lee explained that at the beginning of the artist residency she asked the five African American actors what kind of play interested them and what types of roles they preferred. They explained that they were tired of only finding roles that were race-specific and longed to perform a straightforward naturalistic play that was devoid of racial markers. This idea guided the development of the second narrative, which ap- 
peared to be "on the surface a straight-up naturalistic comedy set at a cocktail party" (Isherwood, "Off-Center").

"Naturalistic" contained generalized stereotypical characters, devoid of race-specific characteristics, that seem to be mildly dysfunctional yet harmless, similar to an episode of the TV sitcom Seinfeld. The five well-dressed white-collar professionals drank cocktails, got advice from the internet, fought with words that held subtle innuendo, and a game called library was their entertainment choice. Lee matched each actor's character in the first narrative to their character in the second narrative. Michael (the host of the party) was played by the Rapper Omar actor. Thomas (who enjoys insulting and embarrassing others) was played by the stand-up comic actor. Desmond (who speaks tersely and appears tense) was played by the Drug Dealer Desmond actor. Thomasina (who advises everyone) was played by the Grandma from Heaven actor. Omar (who is compassionate) was played by the gay hairdresser actor.

In "Stereotype" the plot dealt with the topics of drive-by shooting, drug dealing and addiction, incarceration, and female exploitation. In "Naturalistic" the topics included who went to what university, fad diets and delicate digestive systems, office politics, and romantic relationships. The similar yet different feeling between the two narratives was the strategy Lee used to give the audience "a disorienting sense of continuity between strictly incompatible elements, statements or disclosures" (Hatch, "First" 105).

Sitting in the upscale apartment living room, the characters discussed the various topics then eventually decided to play a game. Lee used the reactions of the characters during the game to bring to light the concept of unconscious racist attitudes. Thomas suggested the game, and Thomasina explained how to play. A book is chosen, and each person composes a sentence that would fit the book and the best sentence wins the game. Desmond considered the game boring. Michael reluctantly agreed to play. Omar worried that the game might lead to mean-spiritedness, especially when Thomas chose a non-fiction book titled Black Magic and selected the chapter about Negro Superstitions. Thomas slyly designated the sentence prompt as "The Negro believes ..." and they all began to compose a sentence.

The behaviors during the writing and the completed sentences revealed direct and indirect hints of bigotry. As Thomasina composed her sentence, she blurted out, "I'm so going to hell for this" (Y. Lee, The Shipment 52). This comment matches the use of phrases like "I am not prejudiced, but..." or the disclaimer "I didn't mean that because, as I told you, I am not a rac- 
ist" that act as "buffers before or after someone states something that is or could be interpreted as racist" (Bonilla-Silva, Racism 57). Tomasina's comment also demonstrated the similar yet different disorientation strategy in that the actor who portrayed a character in heaven during the first narrative also played a character condemning herself to hell in the second.

The point of the game was to write a plausible sentence, but most of the characters wrote sentences that insinuated negative depictions of people of African descent. The first and third sentences that Thomas read aloud concerned the belief in absurd home remedies to cure a disease. During the performances at the Wexner Center in 2008, some people in the audience began to laugh after the actor read each of these sentences. This type of degrading humor is similar to the ubiquitous light humor joke "How many (insert name of group to be insulted) does it take to screw in a light bulb?" that appeared in many old joke books. The second sentence that Thomas read was "The Negro believes" (Y. Lee, The Shipment 52). This sentence seemed to confuse some of the characters. It appeared to be an incomplete game entry or an attempt to humanize the racial group. The stage notes identified the author as Omar, the character who worried that the game might lead to mean-spiritedness.

In contrast to the degrading light humor of the first and third sentences, the remaining two sentences were strongly bigoted statements of racist humor. "The Negro believes that a stutterer may be cured by rubbing him up and down with a raw beef tongue," was attributed to Michael (Y. Lee, The Shipment 52-53). The final sentence, "The Negro believes that a Negro's hands and feet are white because the moon done touched "em in Africa!" (Y. Lee, The Shipment 52-53), elicited laughter from four of the players in succession: first Thomas then Thomasina then Michael. The final character to laugh was Desmond, who laughed loudly in a fashion that was hilarious in itself. Some people in the audiences at the Wexner Center laughed at that point. Desmond's hee-haw type of laughter seemed to supersede or mask the racist element of the sentence. The infectious laughter signaled that the audience had been lured into ignoring psychological self-defense mechanisms connected to political correctness. Lee explained that this was the point in the play that pivoted the momentum to the decisive moment that connected both narratives and set up the strong impact of the final two statements of the play.

During the first narrative, the five black actors had presented characters that exhibited the stereotypes of lower-economic street-smart black urban 
dwellers. Throughout the second narrative, the same five black actors had played well-dressed upper-middle-class urban sophisticates. The audience members had made assumptions about the characters in both narratives based on the actors' appearance and mannerisms. Appearance is a loaded word in that it could mean elements like clothing associated with economic status but it could also mean physical features associated with race. It was the assumptions about the characters and about the actors that came into question as Omar and Desmond delivered their final statements.

When Desmond stopped laughing, Omar said, "I'm sorry. I'm sorry, but I have to say that I'm really uncomfortable with all of this. I just don't think we'd be doing this if there were a black person in the room" (Y. Lee, The Shipment 53). After a pause that was long enough to give the audience time to realize the meaning of Omar's comment, Desmond responded, "I guess that would depend on what kind of black person it was" (Y. Lee, The Shipment 53). Immediately after Desmond's statement the lights went to "(Blackout)" (Y. Lee, The Shipment 53), and the play ended leaving the audience in darkness.

Omar's comment indicated that there were no African American characters. Thus the racial slurs that the characters used were not intra-racial, that is a black person insulting black people, but rather inter-racial or between races. During each of the Wexner Center performances, there were audible gasps from the audience immediately after Omar's statement. The audience assumptions about the characters' race were brought into question by the contradictory nature of the dialogue and the appearance of the actors. By using colorblind casting, Lee allowed the audience to make assumptions about the characters that held stereotypical racial implications until she shocked them with the final dialogue. The aim was to create an awareness of the unconscious application of racial stereotyping through perceived colorblindness.

Race has long been a central descriptor in American identity as indicated by the first census in $1790 . .^{6}$ It is often supplemented by other categorizing aspects such as gender in terms of the male/female binary paradigm, age, ethnicity, religious beliefs, socio-economic status, and sexual orientation/

6 The 1790 census categorized people as free white males, free white females, all other free persons and slaves ("History"). 
identity. ${ }^{7}$ Within the first narrative's stereotypical depiction of racial culture, references to degrading female gender roles, flamboyant sexual orientation, and a welfare class distinction combined to reinforce the commodified images of African Americans often depicted in media. The three sequences displayed characters from a lower socio-economic stratum of society, thus mimicking the media representation of African Americans as ghetto. The third sequence, in particular, through the characters Video Ho and Sashay the hairdresser portrayed the stereotypes of young black women and gay men as promiscuous and sexually immoral.

The second narrative exposed social and cultural attitudes about class distinction, gender, and sexual orientation that are unconsciously applied to race. Desmond's comment on discriminative actions depending on the kind of black person evaluated African Americans on a socio-economic level and represented the assumption that being rich and famous possibly makes some minority individuals acceptable. In terms of gender, the vilest game sentence was offered by Thomasina, the only female character. The combination of the rude black woman stereotype and stereotypical feminine behavior strongly indicated the misogynistic notion that a woman who competes with men will exhibit crude behavior. Contrarily, Omar's gay stereotypical behavior was gentle and genteel. He was the only character whose clothing had color and his behavior fit the stereotype of a person of color "acting white." By showing how other categorizing stereotypes can reinforce the negativity of racial stereotypes, Lee indicated how attitudes of discrimination are not solely based on race but rather on multiple tiers of biases.

\section{Colorblind Commodity Racism}

In a general retail sense, a customer browses through images of products on a website and orders the products represented by the images. These commodity purchasing actions lead to an acceptance of the legitimacy of the products sold on the website. This kind of consumerism process is similar to how mass media markets racial stereotypes. A historical example is

7 On June 15, 2020 the US Supreme Court ruled that Title VII of the Civil Rights Act of 1964 that addressed discrimination in employment on the basis of sex also includes sexual orientation and transgender status (sexual identity) (Hurley, "In landmark"). 
the monetizing of African American folklore by Joel Chandler Harris and Walt Disney who "transformed it into entertainment for white children" and "were less invested in preserving and restoring traditions that were steadily eroding than in turning them into a new form of cultural capital" (Tatar, "Introduction" lxxx). Their renditions of a "kindly black 'Uncle,' a man so worn down by his labors that he is content to settle into the stoic role," set a widely accepted and consumed stereotype (Tatar, "Introduction" lxxx). Similarly, modern media depictions of "African-Americans and other minorities have been shown to influence whites' perceptions of those groups" (Ford, "Effects" 266). When portraying blacks as ghetto dwellers connected to gangs and drugs, they condition the consuming public to expect actual people of color to behave in the same manner. In other words, "AngloAmericans, who have high exposure to negative television portrayals of African Americans, are more inclined to make negative assumptions about other African Americans" (Punyanunt-Carter, "The Perceived" 244).

Colorblind commodity racism is often cloaked by political correctness or encouraged by post-racial attitudes. In an interview, John Del Signore posed the possibility of "a sort of backlash to political correctness in which white people who feel that they're sort of beyond racism will make offensive comments in an ironic way, as if to say, 'We're past this, we can make these jokes because we're so obviously not racist?"; Lee's response designated this possibility as "one of the major things that the cast and I were trying to address, the fact that we're still not there yet" (Del Signore, "Young").

The concept of colorblindness can be a "political tool for the maintenance of the racial order" and like Jim Crow racism "color-blind racism serves today as the ideological armor for a covert and institutionalized system in the post-Civil Rights era" (Bonilla-Silva, Racism 3). In other words, colorblindness is a way for white people to ignore race and "pretend its personal, social, and historical effects" do not exist, thus shifting away from "the exploration of conflicts related to race, ethnicity, and culture" (Williams, "Colorblind"). Gerald Seib suggested "that white people tend to like to think that racial issues have been put behind us. And African Americans do not think that" ("Meet the Press"). One reason for the lack of agreement "is because they conceive terms such as 'racism' very differently. Whereas for most whites racism is prejudice, for most people of color racism is systemic or institutionalized" (Bonilla-Silva, Racism 8). 
The meaning of race is defined and contested throughout society as part of an ongoing process, in which racial definitions and categories are formed, transformed, demolished, and reformed (Omi and Winant, Racial 55-56). The election of a black president in November 2008 seemed to call for such transformation and demolition of racist attitudes. Joshua DuBois defined racist attitudes and actions as "unacknowledged bias and supremacy" and suggested that the necessary cultural change must include "White Americans having an honest conversation about White culture" (DuBois, "We"). However, before any change can occur, awareness must be created. The purpose of The Shipment was to create awareness, especially in the group of people who participate in colorblind commodity racism. Ryan Hatch designated the group as "the American spectator-a spectator who, it would be foolish to forget, has nearly always been construed as white" (Hatch, "First" 104).

\section{Conclusion}

The performing arts have played a role in initiating public dialogue and creating awareness of discriminative societal attitudes and practices related to race. For example, in 1959, Lorraine Hansberry offered an awareness of the effects of segregation and housing discrimination on black families in $A$ Raisin in the Sun. ${ }^{8}$ In 1994 Rita Dove addressed interracial love and the human cost of slavery in The Darker Face of the Earth. ${ }^{9}$ In 2008 Young Jean Lee's The Shipment demonstrated the dehumanizing effects of conscious and unconscious applications of racial stereotypes.

Society is not static and neither is the meaning of race within a society (Omi and Winant, Racial 55-56). The term "first" connected to the election of a black president added a new dimension to the meaning of race in America. Tanner Colby summed the effect of the Obama election on societal attitudes as "Obama's election was astonishing, unprecedented. But what did it really prove other than that it's easier to vote for a black man than to sit and have a beer with one?" (Colby, Some xii). In other words, society professes the need for change but does not do the genuine actions needed to

8 In 1959 houses in some neighborhoods had restricted deeds, which prohibited the sale of the house to people of color or of non-Christian religions (Silva, "Racial").

9 In 1994 less than half of Americans approved of interracial marriages (Carroll, "Most"). 
make a change. So discriminatory attitudes and practices continually need to be highlighted and brought back into the public dialogue.

In 2015 Anna Deavere Smith's play Notes From the Field focused on racial inequality and the flawed justice system. In 2018 Jackie Sibbles Drury's Fairview addressed the systemic issue of how ordinary African Americans of all socio-economic classes are watched, presumed to be threatening and guilty, and in some cases killed just because of the color of their skin. Told from an African American point of view, the play stirs thoughts about "why surveillance affects people of color in a deeper way" (Matin, "The PulitzerWinning"). Also in 2018 Jeremy O. Harris addressed his play Slave Play to interracial relationships and to "exploring so many things that are on people's minds right now" (Shapiro, "With").

The "right now" issue on people's minds in 2008 was a presidential election in which race was a major factor. The Shipment was developed during that election campaign. Its premiere performances at the Wexner Center were held from October 30 to November 2 and on November 4 Barack Obama was elected President of the United States. The wide-spread discussion of that election and talk of a post-racial political era influenced Young Jean Lee's decision to write a black identity politics show. She recognized the importance of bringing the issue of race to the stage at that particular time. After the election, she received an email pertaining to The Shipment that asked, "Now in the age of Obama, do we really need to talk about this 'race stuff' anymore?" (Healy, "An Evening"). This email indicated that there was still a need to address the systemic elements and evolving state of racism.

Ryan Hatch suggested that "ideas about race have always been forged in theatricality's foundry" (Hatch, "First" 104). During the 2020 protests and demonstrations against racial inequality that spread nationwide as well as globally, Anna Deavere Smith explained the role of the theatre in fighting racism as "those of us who are in the humanities and those of us who are in the arts, we kind of stand around the outside and try to knock on the door of the republic to cause the people on the inside" (those with the power to make change) "to do something about it" ("Morning"). The 2008 production of The Shipment was that kind of catalytic knock on the door to create awareness of the effects of racism. Each time The Shipment was performed in Columbus, multiple audience members asked questions and made comments about the production and the topic of racism during the Talk Back sessions. This involvement in discussion seemed to indicate that the play 
had had some degree of impact on some individual's awareness of the effects of racism.

By focusing on The Shipment and connecting it to the social, cultural, and political influences that guided the development process, this article documented the efforts of the playwright and five actors to create awareness of discriminative societal attitudes and practices related to racial stereotyping. Additionally, the article demonstrated how the production fits into the historical landscape of dramatic literature. 


\section{Works Cited}

“A New, 'Post-Racial' Political Era in America." npr.org. 28 Jan. 2008. (accessed, 3 June 2020), http://www.npr.org/templates/transcript/transcript.php?storyId=18489466

Adams, Susan J. "Joyce in Blackface: Goloshes, Gollywoggs and Christy Minstrels in 'The Dead'." De-familiarizing Readings: Essays from the Austin Joyce Conference. Ed. Alan Warren Friedman and Charles Rossman. Leiden, Netherlands: Rodopi, 2009, pp. 33-42.

Als, Hilton. "By the Skin of Our Teeth: Young Jean Lee's Irreverent Take on Racial Politics.” The New Yorker. 26 Jan. 2009. (accessed, 29 May 2020), http://www.newyorker. com/magazine/2009/01/26/by-the-skin-of-our-teeth

---. "Real Gone Girl." The New Yorker. 3 Nov. 2014. (accessed 28 May 2020), http://www. newyorker.com/magazine/2014/11/03/real-gone-girl

Blauner, Robert. "Internal Colonialism and Ghetto Revolt." Racial Oppression in America. New York: Harper \& Rose, 1972, pp. 82-110.

Bonilla-Silva, Eduardo. Racism without Racists: Color-Blind Racism and the Persistence of Racial Inequality in America. New York: Rowman \& Littlefield Publishers, Inc., 2006.

Brillson, Leila. "Young Jean Lee's Theater of the Absurd." Interview Magazine.com. 13 Apr. 2009. (accessed, 28 May 2020), http://www.interviewmagazine. com/culture/youngjean-lee

Carroll, Joseph. "Most Americans Approve of Interracial Marriages." gallup.com. 16 Aug. 2007. (accessed, 13 Feb. 2020), https://news.gallup.com/poll/28417/most-americansapprove-interracial-marriages.aspx

“Celebrities: Can Young Comedians Be Funny Without Using Profanity?” Jet. 5 Sept. 1994: 32-35.

Cervantes, Bobby. "Poll: Obama won $71 \%$ of Asian vote." 12 Dec. 2012. (accessed, 8 June 2020), https://www.politico.com/story/2012/12/poll-obama-won-71-of-asianvote- 085013

Charnas, Dan. The Big Payback: The History of the Business of Hip-Hop. New York: New American Library, 2010.

Chavez, John R. "Aliens in Their Native Lands: The Persistence of Internal Colonial Theory." Journal of World History 22.4 (2011): 785-809.

Chin, Elizabeth. "Commodity Racism." The Wiley Blackwell Encyclopedia of Consumption and Consumer Studies. Ed. Daniel Thomas Cook and J. Michael Ryan. John Wiley \& Sons, 2015, pp. 99-101.

Cho, Jenna. “Asian Americans Take A Stand: Black Lives Matter To Us, Too.” forbes.com. 10 July 2016. (accessed, 30 May 2020), https://www.forbes.com/ sites/jeenacho/2016/07/10/ asian-americans-take-a-stand-black-lives-matter-to-us-too/\#182b68fa55f9

Chou, Rosalind S. and Joe R. Feagin. Myth of the Model Minority: Asian Americans Facing Racism. New York: Rutledge, 2015.

Chow, Kat. "'Model Minority' Myth Again Used As A Racial Wedge Between Asians and Blacks." npr.org. 19 April 2017. (accessed 5 June 2020), https://www.npr.org/sections/codeswitch/2017/04/19/524571669/model-minority-myth-again-used-as-a-racialwedge-between-asians-and-blacks

Clark, Alexis. "How the History of Blackface is Rooted in Racism." history.com. 15 Feb. 2019. (accessed, 30 May 2020), http://www.history.com/news/blackface-history-racismorigins

Colby, Tanner Some of My Best Friends are Black: The Strange Story of Integration in America. New York: Penguin Books, 2012. 
Delgado, Richard, and Jean Stefancic. Critical Race Theory: An Introduction. New York: New York UP, 2012.

Del Signore, John. "Young Jean Lee, Playwright." Gothamist. 22 Jan. 2009. (accessed, 29 May 2020), http://gothamist.com/2009/01/22/young_jean_lee_playwright.php

DuBois, Joshua. "We Need To Talk About White Culture." The Daily Beast. 19 June. 2015. (accessed, 9 June 2020), https://www.thedailybeast.com/we-need-to-talk-about-whiteculture

Dudziak, Mary. Cold War Civil Rights: Race and the Image of American Democracy. Princeton, N.J: Princeton UP, 2000.

Dukes, Kristin Nicole and Sarah E Gaither. "Black Racial Stereotypes and Victim Blaming: Implications for Media coverage and Criminal Proceedings in Cases of Police Violence against Racial and Ethnic Minorities.” Journal of Social Issues 73.4 (2017): 789-807.

Ebrahimji, Alisha and Alicia Lee. "Meet the Asian Americans helping to uproot racism in their communities." CNN. 13 June 2020. (accessed 1 July 2020), https://www.cnn. com/2020/06/13/us/asian-americans-blm-conversations-trnd/index.html

Eligon, John. "The 'Some of My Best Friends Are Black' Defense.” New York Times. 16 Feb. 2019. (accessed, 21 June 2020), https://www.nytimes.com/2019/02/16/sunday-review/ralph-northam-blackface-friends.html

Evan, Nicholas M. Writing Jazz: Race, Nationalism, and Modern culture in the 1920s. New York: Garland Publishing Inc., 2000.

Ford, Thomas E. "Effects of Stereotypical Television Portrayals of African-Americans on Person Perception.” Social Psychology Quarterly 60. 3 (1997): 266-75.

Gallagher, Charles A. "Color-Blind Privilege: The Social and Political Functions of Erasing the Color Line in Post Race America." Race, Gender \& Class 10.4 (2003): 22-37.

Gatlin, Mark. "The Theater of Young Jean Lee: An Experiment in Perturbation." Barley South Review. Jan 2012, (accessed, 30 May 2020), https://barelysouthreview.com/thetheater-of-young-jean-lee-an-experiment-in-perturbation/

Grossberg, Michael. "For Playwright, Racism more than Black-White Issue." Columbus Dispatch. 30 Oct. 2008. (accessed, 28 May 2020), http://www.dispatch.com/content/ stories/weekender/2008/10/30/9A_THEATER30_main.ART_ART_10-30-08_T9_S7BNIEQ.html

Hatch, Ryan Anthony. "First as Minstrelsy, Then as Farce: On the Spectacle of Race in the Theater of Young Jean Lee." CR: The New Centennial Review 13. 3 (2013): 89-114.

Healy, Patrick. "An Evening in Black and White From a Playwright Who is Neither." The New York Times. 28 Jan. 2009. (accessed, 29 May 2020), https://www.nytimes. com/2009/01/28/theater/28lee.html

"History: Index of Questions." United States Census Bureau.(accessed, 25 May 2020), https:// www.census.gov/history/www/through_the_decades/index_of_questions/1790_1.html

Hurley, Lawrence. "In landmark ruling, supreme Court bars discrimination against LGBT workers." Reuters. 15 June 2020. (accessed 30 June 2020), https://www.reuters.com/ article/us-usa-court-lgbt/in-landmark-ruling-supreme-court-bars-discrimination-againstlgbt-workers-idUSKBN23M20N

Isherwood, Charles. "Off-Center Refractions of African-American Worlds." The New York Times. 13 Jan. 2009. (accessed, 4 June 2020), http://www.nytimes.com/ 2009/01/13/theater/reviews/13ship.html

Lee, Esther Kim. A History of Asian American Theatre. Cambridge: Cambridge UP, 2006.

Lee, Young Jean. The Shipment and Lear. New York: Theatre Communications Group, 2010.

Li, Guofang and Lihshing Wang. Model Minority Myth Revisited: An Interdisciplinary Approach to Demystifying Asian American Educational Experiences. Charlotte, NC: Information Age Publishing, Inc., 2008. 
"Living Contraband - Former Slaves in the Nation's Capital During the Civil War." National Park Service. 15 Aug. 2017. (accessed, 22 May 2020), www.nps.gov/articles/living-contraband-former-slaves-in-the-nation-s-capital-during-the-civil-war.htm

Matin, Michel. "The Pulitzer-Winning Play 'Fairview' Is About Being Watched While Black." npr.org. 14 July, 2019. (accessed, 22 May 2020), https://www.npr.org/ 2019/07/14/739057321/the-pulitzer-winning-play-fairview-is-about-being-watchedwhile-black

McClintock, Anne. "Soft-Soaping Empire: Commodity Racism and Imperial Advertising." The Gender and Consumer Culture Reader. Ed. Jennifer R. Scanlon. New York UP, 2000, pp. 129-52.

"Meet the Press Transcript-June 21,2015.” NBC News. 21 June 2015.(accessed, 9 June 2020), https://www.nbcnews.com/meet-the-press/meet-press-transcript-june-21-2015-n379316

“Morning Joe: 'Notes From the Field,' a film on inequality, set to be rebroadcast." MSNBC. 2 June 2020. (accessed, 6 June 2020), https://www.msnbc.com/ morning-joe/watch/notes-from-the-field-a-film-on-inequality-set-to-be-rebroadcast-84231749682.

Omi, Michael, and Howard Winant. Racial Formation in the United States: From the 1960s to the 1990s. New York: Routledge, 1994.

Paik, Irvin. "The East West Players: The First Ten Years are the Hardest." Bridge: An Asian American Perspective 5.2 (1977): 14-17.

Park, Kyeyoung. "Use and Abuse of Race and Culture: Black-Korean Tension in America." American Anthropologist 98.3 (1996): 492-99.

Perea, Juan. "The Black-White Binary Paradigm of Race." Critical Race Theory: The Cutting Edge. Ed. Richard Delgado and Jean Stefancic. Temple UP, 2000, pp. 457-65.

"Performing Arts: Young Jean Lee's Production Company." Wexner Center for the Arts at The Ohio State University. (accessed, 22 May 2020), https://wexarts.org/artist-residency/ young-jean-lees-theater-company

Perse, Elizabeth M. and Jennifer L. Lambe. Media Effect and Society, New York: Routledge, 2017.

Pitner, Barrett Holmes. "Behind the legacy of America's blackface." bbc.com. 5 Feb. 2019. (accessed, 9 June 2020), https://www.bbc.com/news/world-us-canada-47125474

Powell,Shameka. "Relying on Local Contexts to Foster and Thwart Black Student Academic Success: an Ethnographic Account of Teachers Fostering Academic Success for (Some) Black Students." New Directions in Educational Ethnography: Shifts, Problems, and Reconstruction. Ed. Rodney Hopson, William Rodick, and Akashi Kaul. Emerald Group Publishing Limited, 2017.

Punyanunt-Carter, Narissra M. "The Perceived Realism of African American Portrayals on Television.” The Howard Journal of Communications 19 (2008): 241-57.

Rigoglioso, Marguerite. "Unconscious Racial Stereotypes Can Be Reversible." Insights by Stanford Business. 1 Jan. 2008. (accessed, 2 June 2020), https://www.gsb.stanford.edu/ insights/unconscious-racial-stereotypes-can-be-reversible

Rogin, Michael. Blackface, White Noise: Jewish Immigrants in the Hollywood Melting Pot. U of California P, 1998.

Shapiro, Ari. "With 'Slave Play,'A Young Playwright Provokes His Way To Broadway." npr. org. 20 Sept., 2019. (accessed, 4 June 2020), https://www.npr.org/2019/09/20/762785319/ with-slave-play-a-young-playwright-provokes-his-way-to-broadway

Shaw, Helen. "Black Like Them: Nervy Playwright Young Jean Lee Treads the Color Line." Time Out New York. 8 Jan. 2009. (accessed, 29 May 2020), http://www.timeout.com/ newyork/theater/black-like-them 
Shaw, Shaka. "The Difference Between Rap \& Hip-Hop." ebony.com. 19 Sept. 2013. (accessed, 29 May 2020), https:/www.ebony.com/entertainment/the-difference-betweenrap-hip-hop-798/

Sehgal, Parul. "Young Jean Lee's Unsafe Spaces." nytimes.com. 18 July 2018. (accessed, 8 Sept. 2021), https://www.nytimes.com/2018/07/18/magazine/young-jean-lees-unsafespaces.html

Silva, Catherine. "Racial Restrictive Covenants History: Enforcing Neighborhood Segregation in Seattle." The Seattle Civil Rights \& Labor History Project. U of Washington, 2008. (accessed, 29 May 2020), https://depts.washington.edu/ civilr/covenants_report. htm

Soloski, Alexis. "Playwright Young Jean Lee: 'I don't want to have to think about race': Lee's latest work, The Shipment, continues the New Yorker's exploration of race, identity and politics - topics she must face to make herself uncomfortable." Guardian News. 4 June 2014. (accessed, 4 June 2020), http://www.theguardian.com/stage/2014/jun/04/ playwright-young-jean-lee-race-interview

Stoute, Steve. The Tanning of America: How Hip-hop Created a Cuture That Rewrote the Rules of the New Economy. New York: Gotham Books, 2011, pp. xv-xxx.

Tatar, Maria. "Introduction: Recovering a Cultural Tradition." The annotated African American Folktales. Ed. Henry Louis Gates Jr. and Maria Tatar. NY: Liveright Publishing Corp., 2018, pp. liii-xcii.

Treviño, A. Javier. Investigating Social Problems. Sage Publications, Inc., 2015.

Walls, Bryan. "Freedom Marker: Courage and Creativity." pbs.org. 2 Apr. 2018. (accessed, 3 June 2020), http://www.pbs.org/black-culture/shows/list/ underground-railroad/stories-freedom/henry-box-brown/

Williams, Monnica T. "Colorblind Ideology Is a Form of Racism A colorblind approach allows us to deny uncomfortable cultural differences." Psychology Today. 27 Dec. 2011. (accessed, 29 May 2020), https://www.psychologytoday.com/blog/culturally-speaking/201112/colorblind-ideology-is-form-racism

Wright, Richard. "Blueprint for Negro Writing (1937)." Within the Circle:An Anthology of African American Literary Criticism from the Harlem Renaissance to the Present. Ed. Angelyn Mitchell. Duke UP, 1994, pp. 97-106.

"Young Jean Lee." Foundation for Contemporary Arts. 20 Oct. 2016. (accessed, 29 May 2020), http://www.foundationforcontemporaryarts.org/recipients/young-jean-lee 